\title{
O mapeamento cognitivo do Rio de Janeiro na ficção de Rubem Fonseca
}

\author{
Paulo Teixeira \\ Universidade Federal da Bahia
}

\begin{abstract}
Resumo
Fredric Jameson defende que o posicionamento do indivíduo na pós-modernidade torna inevitável o recurso à prática do mapeamento cognitivo, que o autor descreve como um método de localização e de orientação por meio do qual o sujeito, descentrado pela mudança para um novo tipo de espaço, se pode reorientar a si mesmo. Em cada uma das narrativas de Rubem Fonseca, os personagens dependem da sua capacidade de localização e de orientação no espaço urbano do Rio de Janeiro. A ênfase nesses processos revela em que medida este autor reconhece a importância do espaço na construção da subjetividade e nas possibilidades de ação dos seus personagens.
\end{abstract}

Palavras-chave: mapeamento cognitivo; pós-modernidade; Rio de Janeiro; Rubem Fonseca.

\begin{abstract}
Fredric Jameson argues that the positioning of the individual in postmodernity requires the practice of cognitive mapping, which the author describes as a method of localization and orientation through which the subject, decentered by the move to a new type of space, is able to reorient itself. In each of Rubem Fonseca's narratives, the characters depend on their location and orientation in the urban space of Rio de Janeiro. The emphasis in these processes reveals to what extent this author recognizes the importance of space in the construction of subjectivity and in the possibilities of action of his characters.
\end{abstract}

Keywords: cognitive mapping; postmodernity; Rio de Janeiro; Rubem Fonseca.

Recebido em: 17/04/19

Aprovado em: 06/07/19

Na obra Pós-modernismo: a lógica cultural do capitalismo tardio, Fredric Jameson (1997) aborda o desencontro entre a experiência do indivíduo e o espaço pós-moderno da economia globalizada, responsável pela emergência de novos modos de cultura, espaços urbanos e práticas espaciais que não estamos de todo capacitados para entender. Em consequência disso, o autor propõe uma nova técnica, que designa de mapeamento cognitivo, a fim de analisar a relação com o espaço que emerge desse novo paradigma (KUHN, 1998). 
Jameson considera as trajetórias dos corpos pelo espaço como uma maneira de analisar as práticas espaciais. A sua teoria espacial reconhece que "a teoria arquitetônica recente começou a tomar empréstimos da análise da narrativa de outros campos" e perspectiva essa trajetória na forma de "narrativas ou histórias virtuais, que somos chamados a completar e preencher com os nossos próprios corpos e movimentos" (JAMESON, 1997, p. 69).

Nas últimas décadas, o itinerário converteu-se numa figura epistemológica apta a proporcionar uma série de leituras do espaço, a partir da discursividade inscrita no texto literário. Na medida em que o movimento atravessa toda a obra de Rubem Fonseca, afigura-senos pertinente verificar a aplicabilidade da técnica do mapeamento cognitivo à ficção do autor. Os personagens de Rubem Fonseca distinguem-se pelas suas diferentes práticas da mobilidade, ao abrirem caminho por uma metrópole problemática. Os meios de locomoção a que recorrem e, em particular, a prática da caminhada, desempenham um papel importante na configuração do encontro entre a metrópole e a subjetividade individual.

\section{A teoria do mapeamento cognitivo}

A metrópole configura-se como o espaço privilegiado da pós-modernidade, e os seus habitantes oferecem uma multiplicidade de exemplos da extensão da subjetividade através do espaço (PILE, 1996; JAMESON, 1997). Para cada morador da metrópole existe um itinerário diferente, uma trajetória narrativa diferente e, por conseguinte, uma identidade diferente.

A técnica do mapeamento cognitivo permite explorar o modo como a natureza fragmentária da sociedade contemporânea tornou problemática a relação entre o sujeito e a metrópole. Ela constitui um novo modo de percepção das realidades urbanas, que ajuda a compreender a nossa

inserção como sujeitos individuais num conjunto multidimensional de realidades radicalmente descontínuas, cujas molduras vão desde os espaços sobreviventes da vida privada burguesa até o descentramento inimaginável do capital global (JAMESON, 1997, p. 408).

Diante da necessidade de localizar o sujeito dentro da multiplicidade de relações que constituem a metrópole pós-moderna, Jameson afirma que "essas coordenadas estruturais não são mais acessíveis à experiência imediata do vivido e, no mais das vezes, não são nem conceituadas pela maioria das pessoas" (JAMESON, 1997, p. 407). Uma vez que o equipamento de percepção existente se revela incapaz de dominar o novo hiperespaço da pós-modernidade, o autor recorre ao termo esquizofrenia para designar a confusão suscitada por estes novos espaços.

Kevin Lynch (1997) abordou a relação entre a imagem da cidade e a cultura urbana, em particular a relação mental que se estabelece entre o espaço urbano e o habitante da cidade. Lynch desenvolveu uma pesquisa sobre o modo como as pessoas percebem e estruturam as 
cidades com o intuito de se orientarem, assente na ideia de que se encontram na possessão daquilo que designou de mapas mentais: a informação espacial é organizada subjetivamente e auxilia a orientação diária pela cidade. A obra de Lynch é ainda hoje uma referência nos estudos urbanos, pela sua categorização simples da imagem da cidade em cinco tipos de elementos: os pontos nodais, centros de interação a diferentes níveis, que polarizam a prática dos sectores urbanos; os bairros, de que o habitante possui certo conhecimento e nos quais se sente ou não integrado; as vias, canais de observação e itinerários de deslocamento que permitem aceder aos diversos equipamentos e cruzamentos da cidade; os limites, barreiras físicas ou psicológicas que limitam o quadro da vida (a sua transposição por meio de aberturas mais ou menos largas impõe sempre um esforço); os marcos, símbolos que caracterizam e qualificam um espaço, facilitando a orientação.

Lynch defende que, como uma forma de contrariar a possibilidade de desorientação, o habitante da cidade tem a capacidade de organizar espacialmente e de representar mentalmente o espaço urbano. Isto não quer dizer que um mapa cognitivo seja apenas uma representação psicovisual do traçado urbano. O mapeamento cognitivo, em vez disso, é um processo pessoal e subjetivo que, além de organizar o espaço urbano e de o tornar legível, também o impregna de significados. Como refere Angelo Serpa, "a 'cartografia cognitiva' é parte integrante e indissociável das práticas espaciais, 'facilita' nossa vida na resolução dos problemas espaciais cotidianos e norteia nossas estratégias de apropriação do espaço" (SERPA, 2007, p. 177).

Numa descrição da técnica proposta por Jameson, em que recorre a expressões caras à geografia humanística (sentido do lugar e deslugaridade), Robert Tally Jr. afirma que:

A noção de Jameson oferece um modelo de cartografia literária, que [...] se converte num meio segundo o qual um escritor pode substituir o sentido do lugar, ou a deslugaridade do sujeito, pela projeção de uma imagem supraindividual do sistemamundo. Com a estética do mapeamento cognitivo, Jameson chega a uma concepção para o entendimento do mundo e do nosso lugar no mundo, mas também fornece um instrumento por meio do qual o mundo pode ser mudado ou outros mundos podem ser imaginados. $\mathrm{Na}$ verdade, uma espécie de mapeamento cognitivo subjaz ao projeto de representação literária propriamente dito, seja ele concebido em termos de alegoria ou limitado à suposta escrita realista. $\mathrm{O}$ escritor que se propõe mapear o mundo, traçar linhas e sombras nos espaços em branco da página, também torna outros mundos possíveis (TALLY JR., 2013, p. 47-48, tradução nossa).

Na medida em que as narrativas de Rubem Fonseca se mostram favoráveis a uma análise do tipo daquela que foi formulada por Kevin Lynch (1997), podemos considerar a proposta de Jameson e avaliar a aplicabilidade do mapeamento cognitivo ao propósito da reorientação subjetiva dos personagens do autor brasileiro. 


\section{O mapeamento cognitivo do Rio de Janeiro na ficção de Rubem Fonseca}

A teoria do mapeamento cognitivo procede a uma textualização da cidade e concebe esta como um objeto passível de interpretação, cuja leitura depende do posicionamento subjetivo do intérprete (RICOEUR, 1988). Para saber quem somos temos que descobrir primeiro onde estamos: "Bem, o último caminhão deixou nossa amiga em Benfica, numa rua cheia de galpões industriais, por onde ela vagou até que um guarda a interpelou perguntando se estava perdida. Isso tudo foi ela quem me contou" (FONSECA, 1990, p. 72), diz Rosa a Mandrake, ao relatar a chegada de Cila, migrante do Maranhão, sua amante e uma das mulheres assassinadas no romance $A$ grande arte, ao Rio de Janeiro.

A posição do sujeito pode ser determinada, reafirmada, ou mesmo comprometida, por meio de atos de localização e/ou de desorientação. Numa passagem da deslocação de Guedes com o prisioneiro Agenor ao centro antigo do Rio de Janeiro, no romance Bufo \& Spallanzani, o narrador refere que os dois "dali foram para a rua Erasmo Braga e houve um momento em que Agenor quase se perdeu de Guedes no meio daquela massa vibrante de gente" (FONSECA, 1985, p. 232).

A necessidade permanente de se situarem, evidenciada pelos personagens de Rubem Fonseca, revela a subjetividade como um processo ou mesmo como um conflito: "Dei a volta ao mundo, me perdi inúmeras vezes, nem a Morte conhece todas as ruas e praças e estradas do Grande Rio" (FONSECA, 1995, p. 20), confessa o narrador e protagonista do conto "O balão", da coletânea $O$ buraco na parede. O lugar desta disputa, o corpo em movimento no espaço urbano do Rio de Janeiro, torna o processo ainda mais difícil, pois a metrópole não oferece estabilidade e permanência, mas fluxo e mudança (SOJA, 2000). Se ela se encontra em permanente mutação e se recusa a ser imobilizada, o sujeito urbano vai acabar por experimentar e refletir esta instabilidade, o que, por sua vez, conduz a ajustamentos permanentes da subjetividade no processo de transformação da metrópole (PILE, 1996; JAMESON, 1997).

A aplicabilidade do mapeamento cognitivo torna-se evidente se considerarmos o desenvolvimento desse novo subgênero chamado de romance de antidetetive (TANI, 1984), de romance de detetive metafísico (MERIVALE e SWEENEY, 1999), ou, mais simplesmente, de romance policial pós-moderno, como um sintoma da passagem da modernidade para a pósmodernidade. Em Bufo \& Spallanzani, Guedes tenta pôr em prática esse processo, que Jameson descreve como "a reconquista prática de um sentido de localização e de reconstrução de um conjunto articulado que pode ser retido na memória e que o sujeito individual pode mapear e remapear, a cada momento das trajetórias variáveis e opcionais" (JAMESON, 1997, p. 77). Em face disto, Bufo \& Spallanzani também pode ser lido como um romance sobre a tentativa de encontrar sentido no espaço urbano pós-moderno.

Jameson sugere que o posicionamento do indivíduo na pós-modernidade torna inevitável o recurso à prática do mapeamento cognitivo, que o autor descreve como um método de 
localização e de orientação por meio do qual o sujeito, descentrado pela mudança para um novo tipo de espaço, se pode reorientar a si mesmo. Neste sentido, os movimentos de Guedes permitem exemplificar o funcionamento dessa técnica e avaliar o seu alcance. Veja-se o trecho seguinte:

Guedes pegou um ônibus circular na rua General San Martin e voltou à rua Diamantina. Subiu pela rua Faro. Duas horas depois estava num botequim da rua Jardim Botânico, passando a limpo o croqui que fizera, enquanto tomava uma cerveja. Se estivesse em outro automóvel, o assassino, para sair da rua Diamantina, teria descido pela rua Faro, a única que dava mão em direção à Jardim Botânico; se estivesse, ou não, no carro de Delfina, mas se evadira a pé, o assassino teria dois caminhos: descer pela rua Faro ou pela Benjamim Batista, via rua Itaipava, para chegar à rua Jardim Botânico. A rua Faro saía diretamente na Jardim Botânico, mas se o assassino fosse pela Benjamim Batista, para chegar à Jardim Botânico teria que atravessar uma de três ruas: Abade Ramos, Nina Rodrigues ou Nascimento Bittencourt. Além da escadaria que vai dar na praça Pio XI, de onde se pode chegar à Jardim Botânico pelas ruas Oliveira Rocha e Conde de Afonso Celso. Todas essas vias tinham pouco movimento e alguém talvez pudesse ter notado a presença de um estranho na hora deserta em que o crime ocorrera. Infelizmente parecia que todos os prédios daquelas ruas possuíam porteiro eletrônico. Não ia ser fácil encontrar uma testemunha, se é que ela existia (FONSECA, 1985, p. 33-34).

Em muitas das narrativas de Rubem Fonseca, os personagens dependem da sua capacidade de localização e de orientação no espaço urbano do Rio de Janeiro. No conto "A arte de andar nas ruas do Rio de Janeiro", incluído na coletânea Romance negro e outras histórias, Augusto pergunta a Benevides, o chefe do clã de sem-teto que mora na esquina da rua Sete de Setembro com a rua do Carmo:

\footnotetext{
"Como é que se vai nessa rua?"

"Daqui? Você vai até a Igreja da Candelária, em linha reta, chegando lá você pega a Rio Branco, dali vai até a rua Visconde de Inhaúma, entra nela pro lado esquerdo, vai até o largo de Santa Rita onde ela termina e começa a Marechal Floriano, a rua Larga, e pela rua Larga você vai até a rua dos Andradas, pelo lado direito, cruza a rua Leandro Martins, entra na rua Júlia Lopes de Almeida, vai para a esquerda, pra rua da Conceição, segue até chegar na Senador Pompeu, entra pela direita numa travessa Coronel não sei o quê, e sempre pela direita chega na rua do Jogo da Bola. Pergunta por ele, o nome dele é Zé Galinha. Um nego de olho vermelho, sempre cercado de puxasacos. Vai acabar vereador" (FONSECA, 2004, p. 612).
}

As trajetórias através do espaço metropolitano são importantes enquanto dispositivos narrativos de orientação que impulsionam a ação e os personagens. $\mathrm{O}$ foco nos percursos implica uma análise ao tipo de movimento realizado. O que aproxima vários dos personagens de Rubem Fonseca é o uso que fazem da caminhada na metrópole. Os percursos não funcionam apenas tematicamente, mas como um dispositivo retórico. Michel de Certeau (1998) chamou a atenção para a semelhança entre o ato de caminhar e a prática da narratividade. Em primeiro 
lugar, há que considerar a componente dinâmica do movimento, o fato de se estar sujeito à força gravitacional do campo de energia da cidade e de se ser levado ao longo das suas artérias em direção a determinados pontos de atração. Em segundo lugar, o caminhante urbano não efetua uma escolha completamente livre do seu itinerário, mas traça-o num mapa preexistente. $\mathrm{O}$ exemplo seguinte, retirado da obra Vastas emoções e pensamentos imperfeitos, embora situado em Berlim, não poderia ser mais elucidativo:

Fazia frio na rua. Caminhei alguns minutos. Quando encontrei um lugar seguro abri a página do Stadtplan marcada por Plessner.

Seguindo o traçado feito no mapa peguei a Friedrichstrasse e fui até a Unter den Linden. Percorri parte da Unter den Linden e logo cheguei ao canal do rio Spree e vi a Museuminsel, onde ficava o Pergamon. A ilha dos museus situava-se num triângulo em que um dos lados era o Spree (FONSECA, 1988, p. 180).

Noutras palavras, o itinerário seguido pelo protagonista do romance é limitado à rede existente de vias que são identificáveis individualmente e passíveis de ser percorridas. Para Certeau, as narrativas podem ser entendidas como trajetórias espaciais, pois elas selecionam e ligam espaços da mesma maneira que organizam a sequência temporal das ações e os eventos que compõem um enredo.

É determinante para a representação do espaço urbano o fato de o personagem realizar um passeio sem rumo definido ou a sua caminhada assumir a forma de um ritual programado. Em Bufo \& Spallanzani, o prazer que Guedes demonstra pelo ato de caminhar encontra o seu prolongamento no trabalho como detetive. Este ato de caminhar é central no romance e revela-se fundamental para a representação do espaço da capital fluminense. No terceiro capítulo dessa obra, Guedes efetua um longo trajeto ao longo da Zona Sul, desde a rua Barata Ribeiro, em Copacabana, "até à $14^{\mathrm{a}}$ Delegacia, que ficava na rua Humberto de Campos, esquina da Afrânio de Melo Franco, no Leblon, uma caminhada de mais de cinco quilômetros" (FONSECA, 1985, p. 28).

$\mathrm{Na}$ sua qualidade de agente policial, Guedes caminha como um observador crítico, registrando a dinâmica do espaço urbano. A sua caminhada é assinalada por marcos e limites conhecidos (LYNCH, 1997), como o canal que faz a comunicação entre a lagoa Rodrigo de Freitas e o mar, que ele atravessa, conectando com os seus passos os diferentes bairros da Zona Sul:

À direita erguia-se o conjunto de edifícios de sua velha conhecida, a Cruzada São Sebastião. O tira atravessou o canal onde um pescador solitário tentava capturar com uma tarrafa algum peixe que estivesse entrando ou saindo da lagoa Rodrigo de Freitas (FONSECA, 1985, p. 29-30). 
Descrevendo o movimento solitário de Guedes ao longo das ruas ainda desertas de Copacabana, de Ipanema e do Leblon, o narrador faculta-nos a evocação de uma cidade despertando.

As lojas ainda estavam fechadas; mendigos, desempregados, moradores dos vãos das portas já estavam se levantando e preparavam-se silenciosamente para sair dos recantos onde dormiam, antes que os porteiros e serventes começassem a lavar com mangueiras as calçadas de pedra portuguesa. Aquela rua horrenda ficava linda vazia de carros e de transeuntes. Guedes gostava de ruas vazias (FONSECA, 1985, p. 29).

Os romances $A$ grande arte e Bufo \& Spallanzani sublinham o caráter urbano do espaço no qual a ação decorre, descrevendo o labirinto de ruas e de praças. Por sua vez, o conto "A arte de andar nas ruas do Rio de Janeiro" é construído a partir da experiência fundamental de caminhar pelo centro antigo da metrópole, medindo-lhe a topografia emocional. Augusto, o protagonista, deduz o seu conhecimento íntimo da metrópole a partir das próprias experiências ambulatórias. Andar é o meio usado nas táticas espaciais (CERTEAU, 1998) a que recorre para conjurar a memória urbana e os vestígios espaciais da metrópole. Efetuado tendo como agente um caminhante que também é um escritor, que ativamente lembra e imagina, que tece o passado com o presente, o ato de caminhar é o meio que torna possível à história e à espacialidade (SOJA, 1996) convergirem e ganharem vida.

As caminhadas deliberadas de Augusto procuram romper com a racionalidade do planejamento modernista e reavivar as energias adormecidas por meio desse ato de sinalização itinerante, que reproduz a trilha do andarilho, enquanto grava e recupera detalhes que passariam despercebidos a outros habitantes da metrópole. No conto, o protagonista efetua cinco percursos pelo centro do Rio de Janeiro, tendo como ponto de partida o sobrado onde se instalou na rua Sete de Setembro. O trecho seguinte descreve o primeiro dos itinerários seguidos por Augusto:

Da rua Treze de Maio vai para a avenida Rio Branco, deserta. O Theatro Municipal anuncia uma récita de ópera para o dia seguinte, a ópera tem entrado e saído de moda na cidade desde o início do século. [...] Augusto vê um vulto tentando se esconder na rua que fica atrás do teatro, a Manoel de Carvalho, e reconhece um sujeito chamado Hermenegildo que não faz outra coisa na vida senão divulgar um manifesto ecológico contra o automóvel. [...] Os dois caminham até a rua Almirante Barroso, entram à direita, seguindo até a avenida Presidente Antônio Carlos. [...] Depois descem pelo mesmo caminho, entram pela rua da Assembleia e se separam na esquina da Quitanda. Augusto volta para a avenida Rio Branco. Na avenida entra à esquerda, passa novamente pela porta do Municipal, onde se detém, algum tempo, a olhar o desenho do pênis eclético. Vai até a Cinelândia, urinar no McDonald's. [...]

Próximo do Cinema Odeon uma mulher sorri para ele. Mais adiante entra na Casa Angrense, ao lado do Cinema Palácio, e pede uma água mineral. Abre lentamente o copo de plástico e, enquanto bebe em pequenos goles, como um rato, observa as mulheres em volta. Uma mulher que toma um cafezinho é escolhida por ele, porque não tem um dente 
na frente. [...] Caminham juntos, constrangidos. Ele compra um jornal na banca em frente à rua Álvaro Alvim. Vão para o sobrado da chapelaria seguindo pela rua Senador Dantas até o largo da Carioca, vazio e sinistro àquela hora (FONSECA, 2004, p. 600-602).

Augusto enumera metodicamente todos os nomes das ruas por onde passa, desenhando a sua jornada para o leitor. A familiaridade com as particularidades geográficas do Rio de Janeiro torna-se evidente. A sua referência explícita pode ser vista como um meio de incorporar à escrita o traçado urbano do centro, que constitui um espaço vivido (LEFEBVRE, 1999; SOJA, 2000) para o protagonista. No percurso que efetua até ao Campo de Santana, além de enumerar os pontos de referência, o narrador insiste em transmitir o seu conhecimento do espaço urbano, deixando perceber os elementos estruturantes do centro da metrópole:

Augusto vai até à Ramalho Ortigão, passa ao lado da Igreja de São Francisco e entra na rua do Teatro [...] Augusto olha para o último andar do prédio onde morou seu avô [...]. Mas ele não tem pressa em chegar aonde quer, e da rua do Teatro vai à Luiz de Camões para dar uma entrada rápida no Real Gabinete Português de Leitura, ele faz questão que aquela biblioteca tenha seu livro, quando estiver pronto e publicado. [...] Em seguida vai até a avenida Passos, não confundir com a rua Senhor dos Passos, chega ao beco do Tesouro e volta na direção da Visconde do Rio Branco pela Gonçalves Ledo, no meio dos comerciantes judeus e árabes esbarrando na sua freguesia malvestida, e ao chegar à Visconde do Rio Branco deixa o comércio de roupas pelo de objetos usados, mas o que o interessa na Visconde do Rio Branco é o quartel-general do Corpo de Bombeiros, não que aquele fosse o seu destino, mas ele gosta de ver o prédio do Corpo de Bombeiros. [...] Mas os carrões vermelhos não saem e Augusto caminha mais um pouco até a Vinte de Abril e chega ao portão do Campo de Santana, em frente ao largo do Caco e ao Hospital Souza Aguiar (FONSECA, 2004, p. 603-605).

Os itinerários de Augusto incorporam, como vemos, alguns dos mais conhecidos marcos (LYNCH, 1997) do Rio de Janeiro, nos quais cabe destacar, para além do Theatro Municipal e do Real Gabinete Português de Leitura, o Obelisco e o Passeio Público: “Augusto quer comprar um livro para Kelly, mas ela se recusa a entrar no sebo. Vão até a rua São José, dali à rua Graça Aranha, avenida Beira Mar, Obelisco, Passeio Público" (FONSECA, 2004, p. 615).

De fato, na ficção de Rubem Fonseca, os percursos tendem a desenrolar-se em espaços carregados de simbolismo e, muitas vezes, localizados centralmente. É o que sucede com o protagonista do conto "O buraco na parede" da obra homônima:

Eu estava desempregado e ia ler na Biblioteca Nacional todos os dias. Seguia pela Mem de Sá até o largo da Lapa e pegava a rua do Passeio. Eu podia descer pela Evaristo da Veiga, que desembocava na 13 de Maio ao lado do Teatro Municipal, mas preferia a rua do Passeio, que era mais movimentada, tinha mais gente para ver. Da rua do Passeio chegava à praça Mahatma Gandhi, e então praça Floriano, andava um pouco e lá estava a Biblioteca, o prédio mais bonito da cidade (FONSECA, 1995, p. 136). 
A definição do sujeito dentro da geografia de um texto urbano feito de nomes de ruas revela-se de suma importância. Como afirma Roberto Lobato Corrêa, "a toponímia constituise em relevante marca cultural e expressa uma efetiva apropriação do espaço por um dado grupo cultural. É ainda um poderoso elemento identitário. A toponímia, em realidade, articula linguagem, política territorial e identidade" (CORREAA, 2010, p. 176). O modo como o mapa mental do centro antigo é exaustivamente convocado no conto transforma o Rio de Janeiro num texto que se sabe de cor. O fascínio pela sonoridade dos nomes da metrópole permeia quase todas as páginas. Desta forma, os nomes das ruas assumem um papel que, de acordo com Michel de Certeau, lhes confere "a função de articular uma geografia segunda, poética, sobre a geografia do sentido literal, proibido ou permitido" (CERTEAU, 1998, p. 185).

No discurso urbano de Rubem Fonseca, a condição linguística da metrópole é repetidamente afirmada; somos conscientes de que o urbano é, acima de tudo, um espetáculo verbal. Na medida em que o espaço urbano é composto de topônimos, de nomes de ruas e de lojas, do nome próprio dos personagens, o nome transforma-se num depósito textual, no arquivo que permite reconstituir a metrópole informe, tudo aquilo que se revela impossível de mapear. Marc Brosseau acrescenta, a esse respeito, que:

Já no plano simples da onomástica, vários acontecimentos são prefigurados, invertendo, na verdade, a lógica histórica da denominação dos lugares: o nome precede a essência, o sentido. O topônimo vê-se assimilar assim, para além da simples nomeação, uma função primeira de descrição (BROSSEAU, 1996, p. 198, tradução nossa).

Embora os nomes das ruas do Rio de Janeiro definam a configuração local, para os personagens de Rubem Fonseca as ruas apresentam, em primeiro lugar, uma oportunidade de observar os homens e as mulheres (sobretudo as mulheres) e tomar parte da interação social que decorre à sua volta. No trecho antes citado do conto "O buraco na parede", o narrador informa que "a rua do Passeio, que era mais movimentada, tinha mais gente para ver" (FONSECA, 1995, p. 136). No conto "Olivia" da coletânea Ela e outras mulheres, o protagonista afirma: "Minha outra mania é ver as pessoas - mas ver examinando, analisando, entendendo. Olho um homem ou mulher e fico logo imaginando quem é aquela pessoa, qual a sua profissão, idade, que tipo de família tem, onde mora, quanto ganha" (FONSECA, 2006, p. 131-132).

Para além das pessoas, o narrador do conto "A arte de andar nas ruas do Rio de Janeiro" demonstra uma particular predileção pelos espaços intersticiais, pelas ruelas estreitas ou entradas que conectam com as ruas adjacentes ao centro da metrópole, não apenas em resultado da sua simbólica importância na geografia e história política do Rio de Janeiro (ABREU, 2006), mas também porque eles fornecem mais uma figura para a lógica associativa da narrativa sinuosa que tem lugar no conto: "Raimundo vira à esquerda na rua Alexandre Herculano, uma rua 
pequena que só tem uma porta, a porta dos fundos da Faculdade de Filosofia que parece nunca ser usada (FONSECA, 2004, p. 621).

Nesta passagem, o percurso representa a relação do indivíduo com o espaço urbano como um processo de deslocamento e realinhamento que deve ser repetidamente realizado. Cada encontro com as ruas, becos e praças da metrópole implica uma nova adequação às coordenadas espaciais e temporais. $\mathrm{O}$ ato de refazer um percurso anterior envolve um sentido de disjunção espaço-temporal que torna inevitável, por vezes, um desvio do caminho habitual: por esse motivo, a caminhada nunca é a mesma duas vezes.

O narrador sabe que a rota previamente definida não pode eliminar a irrupção do arbitrário nem evitar que alguns acidentes de última hora a perturbem ou the incorporem dados reveladores. É assim que o percurso que o pastor Raimundo efetua, depois de colidir com Augusto à entrada da rua Silva Jardim, se introduz, à maneira de uma mise en abyme, no interior da caminhada do próprio protagonista.

Augusto desaparece, entrando no Hotel Rio. Raimundo treme convulsivamente e cai, desmaiado. Fica estendido algum tempo com a cara na sarjeta, molhado pela forte chuva, uma espuma branca escorrendo do canto da boca, sem despertar a atenção das almas caridosas, da polícia ou dos transeuntes em geral. Afinal a água da sarjeta escorrendo sobre seu rosto o faz voltar a si; Raimundo consegue forças para levantar-se e caminhar tropegamente à procura do demônio; transpõe a praça, cruza a rua Visconde do Rio Branco, avança cambaleante por entre os músicos desempregados que se reúnem na esquina da avenida Passos sob a marquise do Café Capital, do lado oposto ao Teatro João Caetano [...] Raimundo vira à esquerda na rua Alexandre Herculano, uma rua pequena que só tem uma porta, a porta dos fundos da Faculdade de Filosofia que parece nunca ser usada, e afinal entra numa lanchonete na rua da Conceição, onde toma um suco de goiaba e rememora seu inominável encontro. [...] Da praça Tiradentes, descartando parte das instruções de Benevides, Augusto vai para a rua do Jogo da Bola seguindo pela avenida Passos até a avenida Presidente Vargas [...]. (FONSECA, 2004, p. 621-622)

A escrita de Rubem Fonseca, que mistura o real e o imaginário(SOJA, 1996; WESTPHAL, 2007) e oscila entre o fatual e o ficcional, mostra-se igualmente comprometida com uma estrutura retrospectiva e progride numa espiral feita de prolepses, analepses, anedotas e digressões, em vez de por meio de conexões lógicas e lineares. É por isso que o narrador acolhe essa irrupção do aleatório e obsessivamente anota tudo o que o protagonista vê e ouve, tudo aquilo em risco de se perder. Os detalhes mundanos parecem ser procurados por si mesmos, enquanto Augusto ziguezagueia, recomeçando de maneira metódica as suas caminhadas noturnas, cruzando-as com a errância de outros personagens, num esforço para evitar uma resolução final.

Seu Casio Melody toca a música de Haydn das três da madrugada, está na hora de escrever seu livro, mas ele não quer voltar para casa e encontrar Kelly. Solvitur 
ambulando. Vai até o cais dos Mineiros, caminha até a estação das barcas, na praça Quinze, ouvindo o mar bater na muralha de pedra.

Espera o dia raiar, em pé na beira do cais. As águas do mar fedem. A maré sobe e baixa de encontro ao paredão do cais, causando um som que parece um suspiro, um gemido. É domingo, o dia surge cinzento; aos domingos a maioria dos restaurantes do centro não abre; como todo domingo, será um dia ruim para os miseráveis que vivem dos restos de comida jogados fora (FONSECA, 2004, p. 627).

A ênfase nos processos de localização e de orientação revela em que medida Rubem Fonseca reconhece a importância do espaço na construção da subjetividade e nas possibilidades de ação dos seus personagens. A experiência urbana, por sua vez, desempenha um papel determinante na formação das identidades de cada um dos personagens aqui nomeados.

\section{Considerações finais}

O mapeamento cognitivo deve ser entendido como uma técnica susceptível de atribuir uma ordem à relação entre o indivíduo e o espaço metropolitano pós-moderno. Ele ajuda a compreender o espaço urbano do sujeito em nível local e a articular as escalas espaciais diferenciadas da sua experiência até ao nível multinacional. A teoria do mapeamento cognitivo sublinha o caráter da cidade e do espaço humanizado, em termos mais gerais, como algo que não é dado mas produzido (LEFEBVRE, 1999), algo que não é apenas percebido mas também deve ser interpretado (RICOEUR, 1988).

A narrativização do Rio de Janeiro, efetuada por Rubem Fonseca, transforma a metrópole fluminense numa heterogeneidade de textos que dão voz a uma multiplicidade de personagens. A relação que estes estabelecem com o espaço exemplifica, nos textos convocados neste artigo, o modo como o conceito de mapeamento cognitivo pode ser ampliado a fim de acomodar a constituição da identidade do sujeito (PILE, 1996; JAMESON, 1997).

O mapeamento cognitivo da metrópole envolve-se, na obra de Rubem Fonseca, na resistência afirmativa da memória urbana pessoal, já que tantos vestígios da materialidade histórica do Rio de Janeiro surgem incorporados na sua escrita. As narrativas do autor assumem como preocupação documentar essas versões que põem em causa a cartografia oficial e as representações cristalizadas da metrópole. A convocação dos nomes abolidos das ruas e das atividades que nelas tinham lugar constitui uma tapeçaria finamente tecida de presenças ausentes, um mapa imaginário que oscila entre memória e esquecimento, por meio do qual Rubem Fonseca convoca os restos espectrais das encarnações anteriores do Rio de Janeiro, oferecendo uma imagem composta da cidade de sonho, de uma cidade (em tempos) maravilhosa, em contraste com a sua realidade atual. 


\section{Referências}

ABREU, Maurício de. Evolução urbana do Rio de Janeiro. 4. ed. Rio de Janeiro: IPP, 2006.

BROSSEAU, Marc. Des romans-géographes. Paris: L'Harmattan, 1996.

CERTEAU, Michel de. A invenção do cotidiano. 3. ed. Petrópolis: Vozes, 1998.

CORRÊA, Roberto Lobato. A geografia cultural e o urbano. In: ; ROSENDHAL, Z. (Orgs.). Introdução à geografia cultural. Rio de Janeiro: Bertrand Brasil, 2010.

FONSECA, Rubem. Bufo \& Spallanzani. Rio de Janeiro: Francisco Alves, 1985. . Vastas emoções e pensamentos imperfeitos. São Paulo: Companhia das Letras, 1988. . A grande arte. 12. ed. São Paulo: Companhia das Letras,1990. . O buraco na parede. São Paulo: Companhia das Letras, 1995. . Contos reunidos. São Paulo: Companhia das Letras, 2004. . Ela e outras mulheres. São Paulo: Companhia das Letras, 2006.

JAMESON, Fredric. Pós-modernismo: a lógica cultural do capitalismo tardio. 2. ed. São Paulo: Ática, 1997.

KUHN, Thomas S. A estrutura das revoluções cientificas. 5. ed. São Paulo: Perspectiva, 1998. LEFEBVRE, Henri. The production of space. Oxford: Blackwell, 1999.

LYNCH, Kevin. A imagem da cidade. São Paulo: Martins Fontes, 1997.

MERIVALE, Patricia; SWEENEY, Susan Elizabeth (Orgs.). Detecting Texts: the metaphysical detective story from Poe to postmodernism. Philadelphia: University of Pennsylvania Press, 1999.

PILE, Steve. The body and the city: psychoanalysis, space and subjectivity. London: Routledge, 1996.

RICOEUR, Paul. Interpretação e ideologias. 3. ed. Rio de Janeiro: Francisco Alves, 1988.

SERPA, Angelo. O espaço público na cidade contemporânea. São Paulo: Contexto, 2007.

SOJA, Edward W. Thirdspace: journeys to Los Angeles and other real and imagined places. Cambridge: Blackwell, 1996. . Postmetropolis: critical studies of cities and regions. Malden: Blackwell, 2000.

TALLY JR., Robert T. Spatiality. London: Routledge, 2013.

TANI, Stefano. The doomed detective: the contribution of the detective novel to postmodern American and Italian fiction. Edwardsville: Southern Illinois University Press, 1984.

WESTPHAL, Bertrand. La géocritique: réel, fiction, espace. Paris: Minuit, 2007.

\section{Minicurrículo}

Paulo Teixeira é doutor e mestre em Geografia pela Universidade Federal da Bahia, tendo-se licenciado em Geografia e Planeamento Regional na Universidade Nova de Lisboa. 